\title{
PREDICTION OF OIL REMOVAL EFFICIENCY IN COALESCING MODULES OF OIL-WATER SEPARATORS
}

\author{
Edvinas Krugly \\ Viktoras Račys \\ Inga Urniežaitè \\ Kaunas University of Technology, \\ Department of Environmental Engineering, \\ Radvilènu pl. 19, Kaunas, Lithuania
}

\begin{abstract}
Oil pollution is coming to the open waters and wastewater treatment plants mainly with runoff from the streets, filling-stations and other dispersed sources. With the aim to avoid negative impact on the environment, sufficient wastewater treatment technologies and methods have to be used. The main objective of this research - to enable prediction of oil/water separator's efficiency, while changing it's technological factors (hydraulic load, separator's nominal size, coalescing modules configuration and number, etc.). The oil/water separator's efficiency was tested using the test apparatus, in accordance with the standard EN 858-1. Statistical methods for data evaluation and oil/water separator's efficiency prediction were used; as the result, the efficiency was improved 1.5 - 10 times. The main outcome of this research instrument, enabling to design the efficient oil/water separator for specific conditions, bypassing experimental testing.
\end{abstract}

\section{KEY WORDS}

Oil separation; Coalescing modules; Hydraulic load; Modeling.

\section{INTRODUCTION}

Oil, oil products, hydrocarbons of the oil and polycyclic aromatic hydrocarbons are dangerous, toxic and in many cases even carcinogenic. When these products leak into the water, they adversely affect aquatic organisms [1]. They also have negative exposure to human and living environment. Small amounts of oil products continuously leaks to surface runoff in the filling stations, parking lots and car washing plants. In Lithuania according the active Regulation on Run-off Wastewater Management the allowable limit of concentration of oil products in surface run-off must not exceed $5 \mathrm{mg} / 1$ [2]. The surface run-off must to be treated and for this purpose, separators for oil products are used. Usually they are installed together with grid chamber. Oil products removal from the water is performed using various mechanical, physical-chemical, chemical and biological methods, such as settling, centrifugation, filtration, flotation, coagulation, coalescing, sorption, bio-sorption, ozonation and others [3][4]. Most widely applied method is coalescing and its main advantages are the low costs and high treating efficiency [5]. In order to choose and produce appropriate separator for the particular discharge of treated runoff, it is important to choose proper volume for the separator and to ensure appropriate treating efficiency, particular quantity of 
coalescing modules should be installed. The only way to select relevant characteristics is to perform hydraulic tests and determine the proper number of installed coalescing modules in separator. However, hydraulic tests are expensive and require many various resources.

The purpose of this investigation is to determine parameters which influence the efficiency of the separator. It was done by performing hydraulic tests for the separators of one type but having different hydraulic loads. The obtained results were used to develop the prognostic model, enabling prediction of the efficiency of the separator. Changing of various parameters of the separator in this model allow to determine what treatment efficiency will be achieved in each case.

\section{METHODS}

In order to evaluate the efficiency of coalescing filters these tests were performed: determination of hydraulic load, concentration of oil products in the treated water and mathematical modeling of treatment efficiency (prediction).

\subsection{Hydraulic load test}

In order to determine hydraulic load of coalescing modules the tests were performed on manufactured oil-water separators. The investigation was performed according the international standard EN 858-1 "Separator systems for light liquids Part 1. Principles of product design, performance and testing, marking and quality control" [6]. The tests were made in already constructed oil separators. The number of coalescing modules in the separator was changed during the experiment. The tests were made with separators, having $1.51 / \mathrm{s} ; 3 \mathrm{l} / \mathrm{s} ; 61 / \mathrm{s} ; 101 / \mathrm{s} ; 15 \mathrm{l} / \mathrm{s} ; 20 \mathrm{l} / \mathrm{s}$ and $301 / \mathrm{s}$ maximum effluent flow. C class diesel with density $850 \mathrm{~g} / \mathrm{cm}^{3}$ and viscosity $3,32 \mathrm{~mm}^{2} / \mathrm{s}$ was used as a light liquid. According the standard the temperature of water during the experiments was within the limits of $4-20^{\circ} \mathrm{C}$, pH value $\sim 7 \pm 1$. Water flow was constant. At the beginning of the test separator is filled with water, the static water level in the separator is measured and the proper effluent flow, supplied by dosing pums is set. Allowable tolerance of the flow rate is $\pm 2 \%$. Light liquid is added to the water flow by dosing pump at a constant flow rate of $5 \mathrm{ml} / \mathrm{l}(4250 \mathrm{mg} / \mathrm{l})$, with a tolerance of $\pm 5 \%$. Water and light liquid is mixed and is passed to separator. When the water and light liquid flow rates are adjusted, the sampling starts after the running-in period, equivalent to the time, needes to exchange the volume of the water in the separator four times. The scheme of the experimental equipment is provided in Fig. 1. 


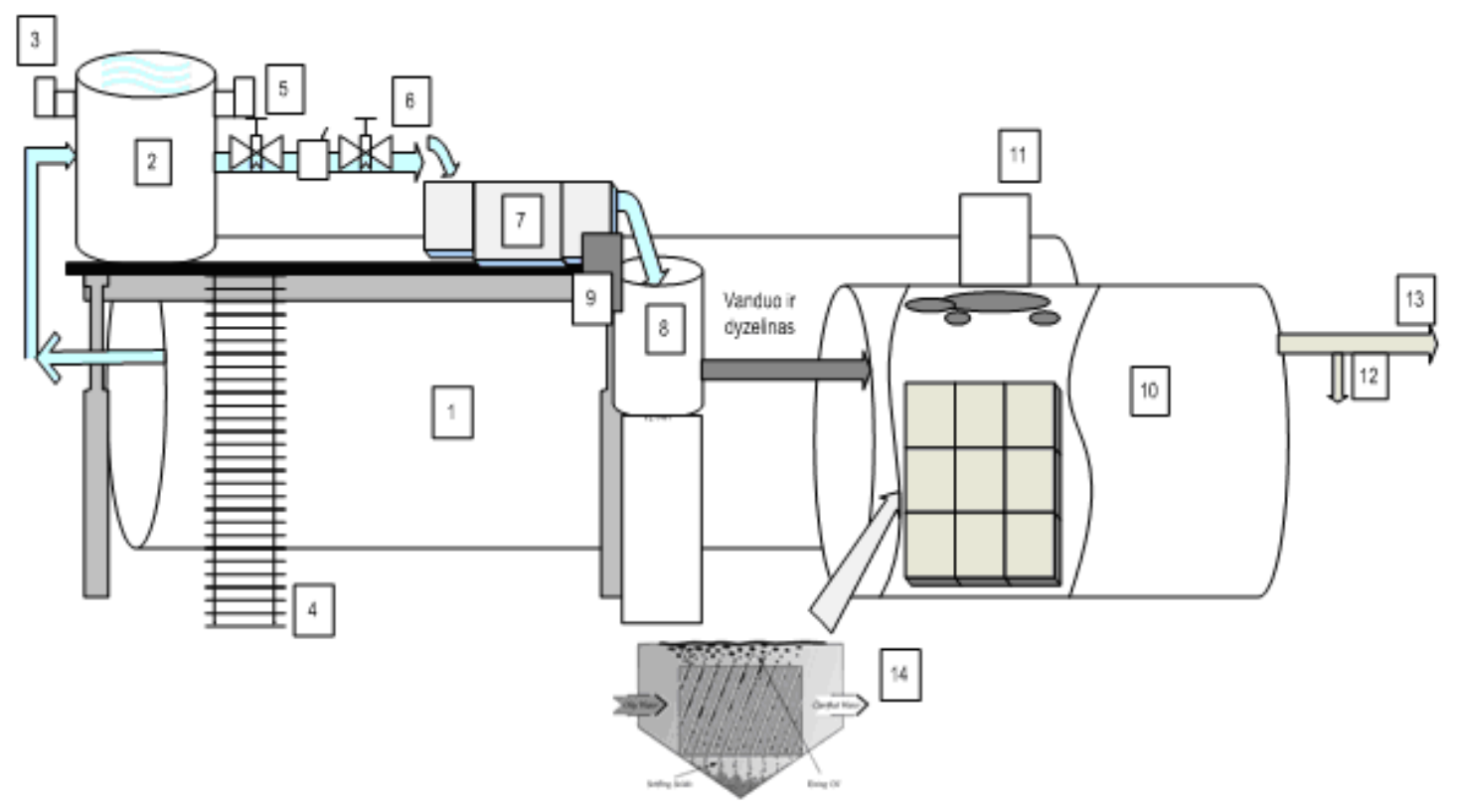

Fig 1. Scheme of the experimental equipment (1- water storage tank, 2 - water supply tank, 3 water overflow pipe, 4 - ladder, 5, 6-valves, 7 - water mixing channel, 8 - mixing tank, 9 - oil dosing unit, 10 - oil separator, 11 - oil removal hole, 12 - sampling pipe, 13 - treated water pipe, 14 - coalescing module)

During the test water flow rate, temperature, $\mathrm{pH}$, static and operating water level in the separator were measured. Water flowing speed inside coalescing modules and hydraulic load of the modules were calculated.

\subsection{Analysis of the light liquid concentration in the effluent samples}

In order to determine concentration of the light liquid residuals in the effluent, analysis of the effluent was performed. Effluent samples were taken using the sampling pipe, situated in the discharge tube. Total of five samples per outlet were taken into 1 liter brown glass bottles and analysis were made in Lithuanian agriculture institute, Agrochemical research centre. Analysis were made according LAND 49-2002 "Quality of water. Infrared spectrometry method for detection of mineral oil (oil products)“ [7]. Analysis were made using the IR spectrometer (Varian 670/680-IR FT-IR spectrometer).

\subsection{Principal component analysis and oil treatment efficiency modeling}

The hypothesis of the analysis is that hydraulic load of the package is the most important factor which influences the efficiency of treatment. The analysis of the obtained experimental research data, experiment conditions change and treatment efficiency prognosis was made. For this purpose principal component analysis and least-squares regression analysis was made.

The principal component analysis allows to determine the impact and it's weight of various process parameters on the most important indicator of the separator: oil products treatment efficiency. When the dependences between various parameters and treatment efficiency are determined, treatment efficiency when using particular influencing parameters sets can be forecasted. 
In order to find linear or polynomial relation between changing parameters and treatment efficiency the treatment efficiency was forecasted using the method of least-squares,.

In order to understand the fundamentals of the process and phenomena, the relation between process technological factors and main process results should be investigated. In the regression analysis dependant variable is that, which behaviour we want to find out, and independent - by which we try to explain the changes of dependent variable. Most important:

- $\quad$ to compare data sets of $X$ and $Y$ properly;

- to reach maximum correlation between $X$ and $Y$.

The efficiency of oil products separators according experimental data was analyzed using software SIMCA-P11 (Umetrics, Sweden). For the final data analysis the data of ten experimental tests were selected. The main purpose was to determine the relation between oil products treatment efficiency and various technological parameters.

\section{RESULTS AND DISCUSSION}

Prognostic model of the treatment efficiency was made and dependence between various technologic parameters and treatment efficiency was made using data of hydraulic testing and analysis of the concentrations of oil product residuals.

\subsection{Parameters of effluent flow and concentration of oil products residuals}

According the active Regulation on Run-off Wastewater Management the allowable limit of concentration of oil products in surface run-off must not exceed $5 \mathrm{mg} / \mathrm{l} \mathrm{limit}$ value. Results of oil products concentrations in the effluent are provided in Table 1. In separators with flow rate of $3 \mathrm{l} / \mathrm{s} ; 6 \mathrm{l} / \mathrm{s}$ and $15 \mathrm{l} / \mathrm{s}$, measured residual oil products concentrations exceeded limit value. During investigation the following parameters were calculated: flow rate $1 / \mathrm{s}$; number of coalescing modules, retention time in separator, min; retention time in coalescing module, min; module flow area $\mathrm{m}^{2}$; length of flow through the module, $\mathrm{m}$; water $\mathrm{pH}$; water temperature ${ }^{\circ} \mathrm{C}$; comparative hydraulic load, $\mathrm{m}^{3} / \mathrm{m}^{3} \cdot \mathrm{s}$; flow velocity in module, $\mathrm{cm} / \mathrm{s}$; flow volume for the module; the number of modules in a row; number of module layers perpendicular to flow direction, static water level, m; operating water level, $\mathrm{m}$, hydraulic losses, $\mathrm{m}$.

Table 1. Concentration of oil residuals

\begin{tabular}{|c|c|c|c|c|}
\hline No. & $\begin{array}{c}\text { Separator's } \\
\text { type/flow rate, } \\
1 / \mathrm{s}\end{array}$ & $\begin{array}{c}\text { Concentration before } \\
\text { treatment Co, mg/l }\end{array}$ & $\begin{array}{c}\text { Concentration after } \\
\text { treatment Ci, mg/l }\end{array}$ & $\begin{array}{c}\text { Treatment } \\
\text { efficiency, \% }\end{array}$ \\
\hline 1 & 1.5 & 4250 & 2.88 & 99.9322 \\
\hline 2 & 3 & 4250 & 9.95 & 99.7659 \\
\hline 3 & 3 & 4250 & 1.76 & 99.9586 \\
\hline 4 & 6 & 4250 & 7.47 & 99.8242 \\
\hline 5 & 6 & 4250 & 4.82 & 99.8866 \\
\hline 6 & 10 & 4250 & 4.51 & 99.8939 \\
\hline 7 & 15 & 4250 & 8.9 & 99.7906 \\
\hline 8 & 15 & 4250 & 3.48 & 99.9181 \\
\hline 9 & 20 & 4250 & 4.17 & 99.9019 \\
\hline 10 & 30 & 4250 & 4.47 & 99.8948 \\
\hline
\end{tabular}


It is determined, that in the separators where residual oil products concentrations exceeded limit value, higher hydraulic load and shorter retention time in coalescing module was assigned. It resulted in a higher residual concentration.

\subsection{Significant technological parameters}

For the full analysis of experimental data course plan was made. The principal component (PC) analysis was performed in order to determine parameters which influence treatment efficiency and their significance. The modeling based on the least-squares method was used aiming to explain dependency between variables and treatment efficiency and to make treatment efficiency prognosis using various values of variables. The variables are technological parameters, listed in the section 3.1. In order to extend the variables set, for more precise description of the investigated data, extended model was used with the squares of additional parameters and cross relations: squares of the flow area in module, hydraulic load and treatment rate; multiplied module flow through rate and treatment rate; multiplied hydraulic load and treatment rate.

The calculations of the coefficient of determination confirmed that principal component analysis is appropriate method for analysis of available data. The results of the principal component analysis allowed determining main parameters, influencing treatment degree. The impact of all the factors on the efficiency of treatment is presented in Table 2. It is observed, that all investigated factors have influence on the efficiency of the treatment of the oil products in water, but some of the factors have significant impact and the others insignificant. Table 2 provides the values of the significance coefficient. If the values of this coefficient are higher than 1, it means that this factor directly influences the process. It was determined, that the efficiency of the treatment mostly is influenced by the load of coalescing module. Thus, the comparative hydraulic load for coalescing module and other associated technological parameters are the main factors, influencing the separator's operation efficiency.

Table 2. Results of PC analysis

\begin{tabular}{|c|l|c|}
\hline No. & Technological parameters & $\begin{array}{c}\text { Coefficient } \\
\text { value }\end{array}$ \\
\hline 1 & Hydraulic load & 1.453 \\
\hline 2 & Retention time in separator & 1.433 \\
\hline 3 & Retention time in module & 1.258 \\
\hline 4 & Flow volume per module & 1.254 \\
\hline 5 & Flow rate through the module & 1.014 \\
\hline 6 & Level, $\mathrm{h}_{0}$ & 0.817 \\
\hline 7 & Quantity of modules & 0.767 \\
\hline 8 & Modular flow-through area & 0.767 \\
\hline 9 & Hydraulic losses & 0.762 \\
\hline 10 & Flow length in the module & 0.646 \\
\hline 11 & Number of modules perpendicular to the flow direction & 0.645 \\
\hline 12 & Level, $\mathrm{h}_{1}$ & 0.617 \\
\hline
\end{tabular}

One of the main parameters, influencing the efficiency of the treatment is retention time in the module. This can be explained by the time, which is required to form bigger drops of oil by coalescing so that they could faster rise to surface. The values in Table 2, show that the first five listed parameters have significant influence and coefficient, higher than one: 
comparative hydraulic load, retention time in separator, retention time in module; flow volume per module; flow rate through the module. These parameters directly affect the efficiency of water treatment in the separator.

\subsection{Prognosis of treatment efficiency}

The least squares method is used to forecast the efficiency of treatment, using particular selected technological parameters - variables. The test of the least square method applicability approved suitability of this method application to the analyzed data.

This method allows forecast of the efficiency of treatment by changing various above mentioned parameters. Prognostic model is designed for separators which did not meet the the treatment efficiency requirements, as after treatment process residual concentration of oil products exceeded allowable limit. $31 / \mathrm{s}-9.95 \mathrm{mg} / \mathrm{l} ; 6 \mathrm{l} / \mathrm{s}-7.47 \mathrm{mg} / \mathrm{l}$ and $15 \mathrm{l} / \mathrm{s}-8.90$ $\mathrm{mg} / \mathrm{l}$ respectively. For each of these three separators various configurations of technological parameters were applied. For separator with flow rate of $31 / \mathrm{s}$, configuration of coalescing modules arrangement was changed. The rate of the flow in the modules decreased two times and efficiency of treatment increased ten times. For separator with flow rate of $61 / \mathrm{s}$, the number of coalescing modules was increased. As a result, efficiency of treatment increased 1.6 times. For separator with flow rate of $15 \mathrm{l} / \mathrm{s}$, the number of coalescing modules was increased and their arrangement was changed. Treatment efficiency in this case increased 2.7 times. Residual concentrations of oil products before modeling, after modeling and after technological changes in the real separator are presented in Table 3.

Table 3. Residual concentration of oil products

\begin{tabular}{|c|c|c|c|}
\hline $\begin{array}{c}\text { Separator's } \\
\text { type/flow } \\
\text { rate, } 1 / \mathrm{s}\end{array}$ & $\begin{array}{c}\text { The residual } \\
\text { concentration before } \\
\text { modeling, } \mathrm{mg} / \mathrm{l}\end{array}$ & $\begin{array}{c}\text { The residual } \\
\text { concentration obtained } \\
\text { by modeling, mg/l }\end{array}$ & $\begin{array}{c}\text { The residual concentration } \\
\text { after the technological } \\
\text { changes, } \mathrm{mg} / 1\end{array}$ \\
\hline 1,5 & $9.95 \pm 1.9$ & $0.99 \pm 0.18$ & $1.76 \pm 0.40$ \\
\hline 3 & $7.47 \pm 0.4$ & $4.90 \pm 0.24$ & $4.82 \pm 0.98$ \\
\hline 15 & $8.90 \pm 1,5$ & $4.53 \pm 0.55$ & $3.48 \pm 1.56$ \\
\hline
\end{tabular}

After making various modifications in separators and repeating hydraulic tests, it was determined that residual concentration of oil products does not exceed limit value. Residual concentrations, calculated using the model are very close to the obtained during experimental tests, after modifications in separators.

\section{CONCLUSION}

The performed research on efficiency of treatment in oil separators revealed, that each set of the process technological parameters affects the efficiency of treatment differently. Statistical analysis of experimental investigation data showed that the hydraulic load and the rate of water flow has the biggest influence on efficiency. After determining the main parameters, influencing the efficiency of treatment, the recommendations for forecasting the separator's efficiency was developed. These recommendations allow economical and fast method for choosing required separator's parameters on purpose to achieve proper degree of oil products removal. 


\section{ACKNOWLEDGEMENT}

The authors would like to thank JSC "Eneka" for technical support and Msc. Jurate Saltiene for her contribution to this research.

\section{REFERENCES}

[1] Burger, J., 1997. Oil Spills. Rutgers University Press. ISBN 0813523389.

[2] Paviršinių nuotekų tvarkymo reglamentas, 2007. (Regulation on Run-off Wastewater Management) Lithuanian Ministry of Environment, 2007, D1-193, Vilnius. (in Lithuanian)

[3] Soli. J., Shyam. R., 2008. Wastewater Treatment for Pollution Control and Reuse. McGraw-Hill PublishingCompany, ISBN 0070620997.

[4] Veenstra, J.N., Mohr, K.S., Sanders, D.A., 1998. Refinery Wastewater Management Using Multiple - Angle Oil Water Separators International Petroleum Environment Conference, Albuquerque, New Mexico 1998.

[5] Ji, F., Li, C., Dong, X., Li, Y., Wang, D. 2009 Separation of oil from oily wastewater by sorption and coalescence technique using ethanol grafted polyacrylonitrile, Journal of Hazardous Materials, Vol. 164, 1346-1351.

[6] EN 858-1 Separator systems for light liquids (e.g. oil and petrol) - Part 1: Principles of product design, performance and testing, marking and quality control. 2002. CEN, Brussels.

[7] LAND 49-2002. Vandens kokybė. Infraraudonuju spindulių spektrofotometrijos metodas mineralinei naftai (naftos produktams) nustatyti. 2002. (Water quality. Infrared spectrophotometric method for determination of oil products) Lithuanian Ministry of Environment, Vilnius. (in Lithuanian) 